\title{
Reduction of dislocation density in mismatched SiGe/Si using a low-temperature Si buffer layer
}

\author{
K. K. Linder, F. C. Zhang, J.-S. Rieh, and P. Bhattacharya ${ }^{\text {a) }}$ \\ Department of Electrical Engineering and Computer Science, Solid State Electronics Laboratory, \\ University of Michigan, Ann Arbor, Michigan 48109-2122 \\ D. Houghton \\ SiGe Microsystems, Inc., Nepean, Ontario, K2H 9C4, Canada
}

(Received 26 February 1997; accepted for publication 14 April 1997)

The reduction of the dislocation density in relaxed $\mathrm{SiGe} / \mathrm{Si}$ heterostructures using a low-temperature $\mathrm{Si}(\mathrm{LT}-\mathrm{Si})$ buffer has been investigated. We have shown that a $0.1 \mu \mathrm{m}$ LT-Si buffer reduces the threading dislocation density in mismatched $\mathrm{Si}_{0.85} \mathrm{Ge}_{0.15} / \mathrm{Si}$ epitaxial layers as low as $\sim 10^{4} \mathrm{~cm}^{-2}$. Samples were grown by both gas-source molecular beam epitaxy and ultrahigh vacuum chemical vapor deposition. (C) 1997 American Institute of Physics.

[S0003-6951(97)03424-4]

$\mathrm{SiGe/Si}$ heterostructures have gained considerable attention for both electronic and optoelectronic applications due to their compatibility with existing Si technology. ${ }^{1-5}$ In particular, there are device applications where a strained $\mathrm{Si}$ channel layer of a field-effect transistor needs to be grown on relaxed SiGe to produce a type II heterostructure band lineup. Producing relaxed, nearly defect-free $\mathrm{SiGe}$ alloys has been difficult due to the $4 \%$ mismatch between $\mathrm{Si}$ and Ge. Above the critical thickness, threading dislocations form in the SiGe epilayer, resulting in material degradation and poor device performance. ${ }^{6}$ Both superlattices and step-graded layers have been used as techniques to reduce the strain energy while minimizing threading dislocations. ${ }^{7-13}$ While some reduction was obtained, ${ }^{7-9}$ the dislocation densities are still too high $\left(\sim 10^{9} \mathrm{~cm}^{-2}\right)$ for any practical device application.

Recent reports indicate that the use of amorphous, polycrystalline, and low-temperature buffer layers can significantly reduce dislocation densities in nitride, InAlAs/InP, and SiGe technologies. ${ }^{14-16} \mathrm{We}$ have investigated the use of a low-temperature $\mathrm{Si}$ (LT-Si) buffer layer for reducing the threading dislocation density in relaxed $\mathrm{SiGe}$ heterostructures. We report the characterization of these heterostructures grown by both gas-source molecular beam epitaxy (GSMBE) and ultrahigh vacuum chemical vapor deposition (UHVCVD), and of heterojunction bipolar transistors (HBTs) using LT-Si buffers.

A number of relaxed $\mathrm{SiGe}$ samples with and without the LT-Si buffer layer were grown by GSMBE. Pure $\mathrm{Si}_{2} \mathrm{H}_{6}$ and solid Ge were used as source materials. The samples were grown on (100) $p^{+}$Si substrates. Each sample consists of a $0.1 \mu \mathrm{m} \mathrm{Si}$ layer grown at $700{ }^{\circ} \mathrm{C}$ followed by a $0.1 \mu \mathrm{m}$ LT-Si buffer layer grown at $450{ }^{\circ} \mathrm{C}$. A $0.5 \mu \mathrm{m} \mathrm{Si}_{0.85} \mathrm{Ge}_{0.15}$ layer was then grown at $570{ }^{\circ} \mathrm{C}$. Growth of the entire structure was monitored by in situ reflection high-energy electron diffraction measurements. The image displayed a streaked $(2 \times 1)$ pattern during growth of $\mathrm{Si}$ at $700{ }^{\circ} \mathrm{C}$, which turned spotty during growth of the LT-Si buffer layer. The streaked pattern was restored after a few monolayers of growth of SiGe at $570{ }^{\circ} \mathrm{C}$. The control sample consists of a $0.1 \mu \mathrm{m} \mathrm{Si}$ layer also grown at $700{ }^{\circ} \mathrm{C}$ followed by a $0.5 \mu \mathrm{m}$

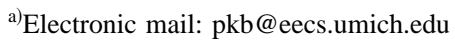

$\mathrm{Si}_{0.85} \mathrm{Ge}_{0.15}$ layer grown at $570{ }^{\circ} \mathrm{C}$. Each $\mathrm{SiGe}$ sample thickness exceeds the thermodynamically stable critical thickness of $0.4 \mu \mathrm{m} .{ }^{17}$ The threading dislocation densities were examined by transmission electron microscopy (TEM) using a JEOL 2000-FX microscope with an accelerating voltage of $200 \mathrm{kV}$. Both cross-section TEM and plan-view imaging were performed.

Bright-field cross-section (200) imaging of heterostructures without and with the LT-Si buffer layer are shown in Figs. 1(a) and 1(b), respectively. In the samples without the LT-Si buffer layer, the threading dislocations propagate throughout the alloy layer, as expected. An examination by bright field plan-view (022) imaging indicates a threading dislocation density of $7.56 \times 10^{9} \pm 2.08 \mathrm{~cm}^{-2}$ in the sample

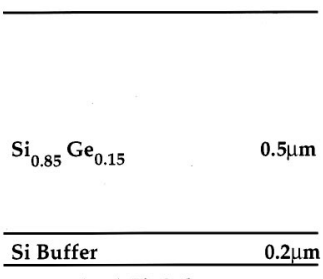

(100) Si Substrate

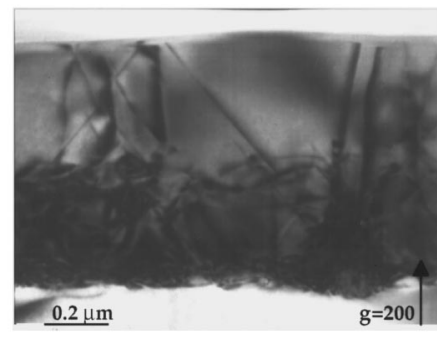

(a)
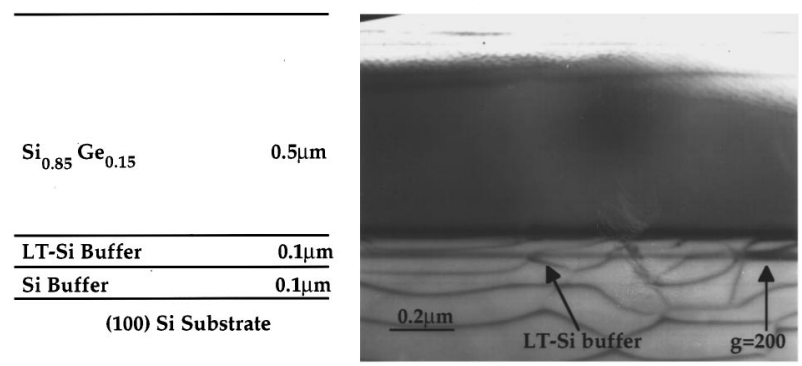

(b)
FIG. 1. Bright field (200) cross-section TEM images of $0.5 \mu \mathrm{m}$ thick $\mathrm{Si}_{0.85} \mathrm{Ge}_{0.15}$ grown at $570{ }^{\circ} \mathrm{C}$ on (100) $\mathrm{Si}$ substrates (a) without any lowtemperature $\mathrm{Si}(\mathrm{LT}-\mathrm{Si})$ buffer and (b) with a $0.1 \mu \mathrm{m}$ LT-Si buffer layer grown at $450{ }^{\circ} \mathrm{C}$. Both samples have a $0.1 \mu \mathrm{m}$ Si buffer layer grown first on the substrate at $700{ }^{\circ} \mathrm{C}$. 


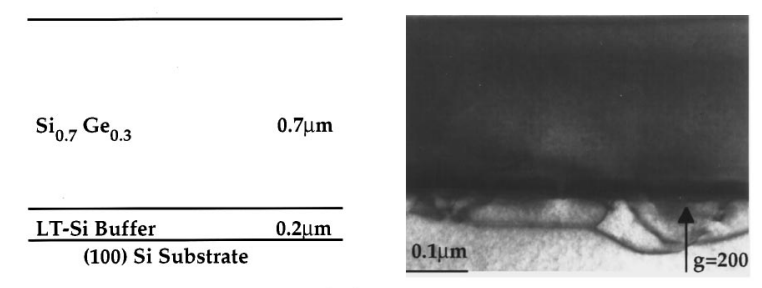

(a)

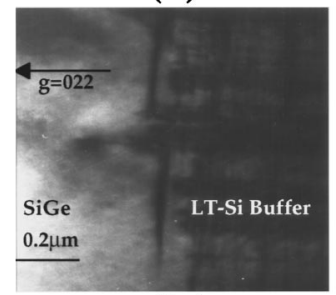

(b)

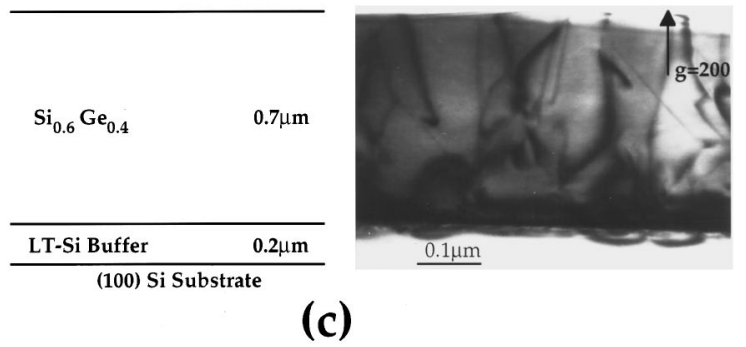

FIG. 2. TEM images of SiGe samples grown on (100) Si substrates by UHV-CVD. The samples contain a $0.2 \mu \mathrm{m}$ LT-Si buffer layer grown at $425{ }^{\circ} \mathrm{C}$ on the substrate followed by $0.7 \mu \mathrm{m}$ of SiGe grown at $525^{\circ} \mathrm{C}$. (a) and (b) show the bright field (200) cross-section and (022) plan-view TEM of a $\mathrm{Si}_{0.7} \mathrm{Ge}_{0.3}$ layer, respectively. (c) shows the cross section of a $\mathrm{Si}_{0.6} \mathrm{Ge}_{0.4}$ layer.

without the LT-Si buffer layer. It is evident in the sample with the LT-Si buffer layer, Fig. 1(b), most or all of the threading dislocations are prevented from propagating into the SiGe layer. These results, along with an examination by plan-view imaging of the same structure, indicate that the threading dislocation density is $\leqslant 10^{4} \mathrm{~cm}^{-2}$ in the SiGe epilayer. Room-temperature Hall measurements were performed on $1 \mu \mathrm{m}$ thick boron doped $\left(3.4 \pm 1.8 \times 10^{17} \mathrm{~cm}^{-3}\right)$ $\mathrm{Si}_{0.7} \mathrm{Ge}_{0.3}$ samples. The hole mobility increased from 160 $\pm 18 \mathrm{~cm}^{2} \mathrm{~V}^{-1} \mathrm{~s}^{-1}$ to $200 \pm 2.5 \mathrm{~cm}^{2} \mathrm{~V}^{-1} \mathrm{~s}^{-1}$ by including the LT-Si buffer layer.

Motivated by these results, we then examined the effectiveness of the LT-Si buffer layer for several relaxed $\mathrm{Si}_{1-x} \mathrm{Ge}_{x}$ samples with varying $x$ grown on (100) $p^{+} \mathrm{Si}$ substrates by UHV-CVD. Ultralarge scale integration grade silane $(100 \%)$ and germane (10\% in helium) were used as material gas sources. The samples consist of an initial 0.2 $\mu \mathrm{m}$ LT-Si buffer layer grown at $425^{\circ} \mathrm{C}$ followed by $0.7 \mu \mathrm{m}$ $\mathrm{Si}_{0.7} \mathrm{Ge}_{0.3}$ and $\mathrm{Si}_{0.6} \mathrm{Ge}_{0.4}$, respectively, grown at $525^{\circ} \mathrm{C}$. Bright field (200) cross-section and (022) plan-view imaging of the $\mathrm{Si}_{0.7} \mathrm{Ge}_{0.3}$ sample, shown in Figs. 2(a) and 2(b), indicate a near defect-free $\mathrm{SiGe}$ region. The bright field (022) plan-view image of the same sample, shown in Fig. 2(b), indicates that the dislocations are contained within the LT-Si buffer layer. For higher $(40 \%)$ Ge containing samples, as shown in Fig. 2(c), optimization of the LT-Si buffer layer thickness for minimizing the threading dislocation density is under investigation.

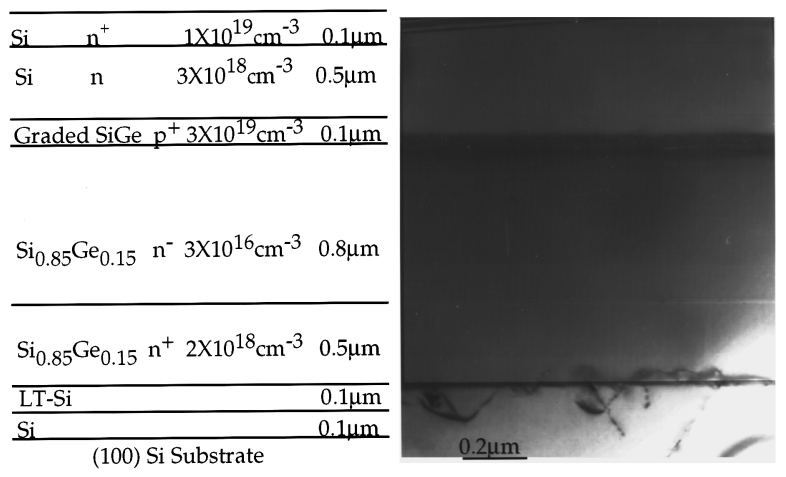

(a)

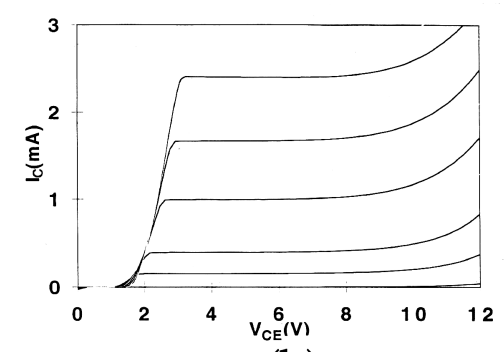

(b)

FIG. 3. (a) Cross-section TEM image and (b) dc common-emitter currentvoltage characteristics of a $n-p-n \mathrm{SiGe} / \mathrm{Si}$ bipolar transistor grown with the LT-Si buffer grown at MBE.

Double crystal x-ray measurements of the $\mathrm{Si}_{0.85} \mathrm{Ge}_{0.15}$ layer without and with LT-Si buffer layers show that the width (full width at half-maximum) of the rocking curve corresponding to the alloy peak is reduced from $450 \operatorname{arcs}$ to 371 arc s, respectively.

The mechanism for threading dislocation reduction is still under investigation. We suspect that because of the low growth temperature, a large number of point defects are generated in the LT-Si buffer layer. As the misfit dislocations propagate through the LT-Si layer, they become trapped by the defects and are annihilated.

From Fig. 1(b), one should note the existance of threading dislocations in the substrate region just below the LT-Si buffer layer. We believe that the threading dislocations found deep inside the substrate are generated from the activation of Frank-Read sources, which can relieve the strain in the SiGe epilayer. ${ }^{18}$ The bowing mechanism is also observed in samples using graded layers and superlattices to relieve strain. $^{10,19}$

We have grown and fabricated preliminary $\mathrm{SiGe} / \mathrm{Si}$ $n-p-n$ HBTs with LT-Si buffer layers. The complete heterostructure is shown in Fig. 3(a). It can be seen that the active region of the structure is defect-free although the area of $10 \times 10 \mu \mathrm{m}^{2}$ is shown in Fig. 3(b). The dc current gain is $\sim 6$ and the breakdown voltage is more than $10 \mathrm{~V}$. The $V_{c e}$ offset voltage is $\sim 1.5 \mathrm{~V}$ and the Early voltage is approximately $1000 \mathrm{~V}$.

Recent reports have shown that higher electron mobilities are measured in strained $\mathrm{Si}$ grown on relaxed $\mathrm{SiGe}$ than in bulk $\mathrm{Si}$ due to band splitting at the $\mathrm{SiGe} / \mathrm{Si}$ heterojunction. $^{20,21}$ Strained $\mathrm{Si}$ surface channel $n$-metaloxide-semiconductor field-effect transistors grown on re- 
laxed SiGe, which exploit the LT-Si buffer layer are being investigated.

In conclusion, we have investigated a new defect density reduction method for $\mathrm{SiGe}$ heterostructures that uses a LT-Si buffer layer. Both gas-source MBE and UHV-CVD technologies have demonstrated threading dislocation densities as low as $10^{4} \mathrm{~cm}^{-2}$. Preliminary SiGe/Si $n-p-n$ HBTs exploiting the LT-Si buffer layer have been grown and fabricated.

The work is supported by the Air Force Office of Scientific Research under Grant No. F49620-95-1-0013 and by an AASERT Fellowship (AFOSR) under Grant No. F49620-940404.

${ }^{1}$ A. Pruijmboom, J. W. Slotboom, D. J. Gravesteijn, C. W. Fredriksz, A. A. van Gorkum, R. A. van de Heuvel, J. M. L. van Rooij-Mulder, G. Streutker, and G. F. A. van de Walle, Electron. Device Lett. 12, 357 (1991).

${ }^{2}$ K. Ismail, S. F. Nelson, J. O. Chu, and B. S. Meyerson, Appl. Phys. Lett. 63, 660 (1993).

${ }^{3}$ K. Ismail, J. O. Chu, and B. S. Meyerson, Appl. Phys. Lett. 64, 3124 (1994).

${ }^{4}$ K. Ismail, B. S. Meyerson, and P. J. Wang, Appl. Phys. Lett. 58, 2117 (1991).

${ }^{5}$ K. D. Hobart, F. J. Kub, N. A. Papanicoloau, W. Kruppa, and P. E. Thompson, J. Cryst. Growth 157, 2115 (1995).
${ }^{6}$ K. Ismail, F. K. LeGoues, K. L. Saenger, M. Arafa, J. O. Chu, P. M. Mooney, and B. S. Meyerson, Phys. Rev. Lett. 73, 3447 (1994).

${ }^{7}$ P. M. Mooney, J. L. Jordan-Sweet, J. O. Chu, and F. K. LeGoues, Appl. Phys. Lett. 66, 3642 (1995).

${ }^{8}$ M. A. Lutz, R. M. Feenstra, F. K. LeGoues, P. M. Mooney, and J. O. Chu, Appl. Phys. Lett. 66, 724 (1995).

${ }^{9}$ J. H. Li, V. Holy, G. Bauer, J. F. Nützel, and G. Abstreiter, Appl. Phys. Lett. 67, 789 (1995).

${ }^{10}$ F. K. LeGoues, B. S. Meyerson, and J. F. Morar, Phys. Rev. Lett. 66, 2903 (1991).

${ }^{11}$ R. Hull, J. C. Bean, R. E. Leibenguth, and D. J. Werder, J. Appl. Phys. 65, 4723 (1989).

${ }^{12}$ G. Kissinger, T. Morgenstern, G. Morgenstern, and H. Richter, Appl. Phys. Lett. 66, 2083 (1995).

${ }^{13}$ F. K. LeGoues, Phys. Rev. Lett. 72, 876 (1994).

${ }^{14}$ H. Chen, L. W. Guo, Q. Cui, Q. Hu, Q. Huang, and J. M. Zhou, J. Appl. Phys. 79, 1167 (1996).

${ }^{15}$ J. M. Fernandez, J. Chen, and H. H. Weider, J. Vac. Sci. Technol. A 11, 889 (1993).

${ }^{16}$ E. Scheid, L. K. Kouassi, R. Henda, J. Samitier, and J. R. Morante, Mater. Sci. Eng. B 17, 185 (1993).

${ }^{17}$ E. Kasper, H.-J. Herzog, and H. Kibbel, Appl. Phys. 8, 199 (1975).

${ }^{18}$ J. P. Hirthe and J. Lothe, Theory of Dislocations, 2nd ed. (Wiley, New York, 1982).

${ }^{19}$ B. S. Myerson, K. J. Uram, and F. K. LeGoues, Appl. Phys. Lett. 53, 2555 (1988).

${ }^{20}$ T. Vogelsang and K. R. Hofmann, Appl. Phys. Lett. 63, 186 (1993).

${ }^{21}$ D. Nayak and S. K. Chun, Appl. Phys. Lett. 64, 2514 (1994). 